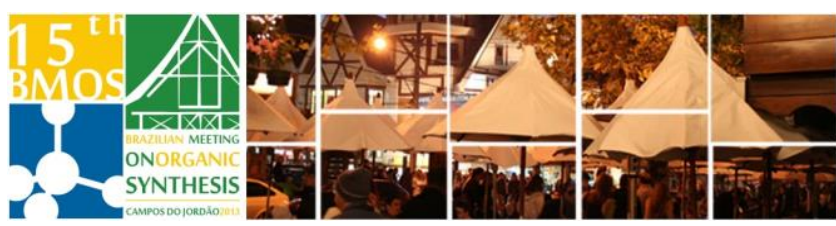

\title{
Facile one-pot synthesis of novel 1,2,4-Triazin-5-one from intramolecular cyclization
}

\author{
Fernanda A. Rosa ${ }^{\star}$, Davana S. Gonçalves, Michael J. V. da Silva, Camila S. S. Tozatti, \\ Gisele F. Gauze
}

Estereoquímica de Compostos Orgânicos e Docking Molecular (ECO), Departamento de Química (DQI), Universidade Estadual de Maringá, CEP 87.020-900, Maringá, PR, Brasil.

*e-mail corresponding author: farosa@uem.br

Keywords: intramolecular cyclization, heterocycles, triazinones.

\section{INTRODUCTION}

The triazinones are integral part of class bioactive in the heterocyclic compounds. In particular the 1,2,4Triazin-5-ones are very important in class of these compounds and have attracted particular attention in the pharmaceutical and agrochemical industries, as have exhibited potential activity antitumor ${ }^{[1]}$, anticancer, antiulcer, and anti-inflammatory effects, activity as herbicides, desiccants, defoliants, plant growth regulators and insecticides ${ }^{[2]}$.

Numerous methods for the synthesis of these compounds have been published, among them, there are condensation reactions of hydrazide and hydrazones with primary amines or acetals derivatives and cyclization obtained by treatment thermal and in the presence of acid ${ }^{[3-5]}$.

In this work, we attempted to synthesis 1,2,4- triazin5-ones through a new method using condensations in the 2-hydrazonopropanehydrazide (1) with $\mathrm{N}, \mathrm{N}$ Dimethylformamide dimethyl acetal (DMFDMA) and intramolecular cyclization by acid catalyzed.

\section{RESULTS AND DISCUSSION}

Was used as starting material the 2hydrazonopropanehydrazide (1) (Scheme 1) as described in the literature ${ }^{[6]}$, but with modifications in their synthesis ${ }^{[7]}$. The synthesis of the precursor compounds 2 and 3 were made through of the condensation in the starting material with DMFDMA in three different conditions (Scheme 1) varying the amount of DMFDMA, reaction midst and reaction time, as follows conditions $i$, obtaining the compound (2), ii and iv yielding (3). These precursors were subjected to intetramolecular cyclization upon attack of the hydrazide $\mathrm{NH}$ group at the iminic carbono of the hydrazone, leading to triazinone (4). The synthesis of the triazinone is also possible by onepot reaction employing condition vi, where started from (1) occurring condensation with 2 equivalents of DMFDMA, employing a Lewis acid resulting in the intramolecular cyclization without isolating the intermediates, with excellent yield. The compounds were characterized by Nuclear Magnetic Resonance (NMR) of ${ }^{1} \mathrm{H},{ }^{13} \mathrm{C}, \mathrm{HSQC}$, NOESY.

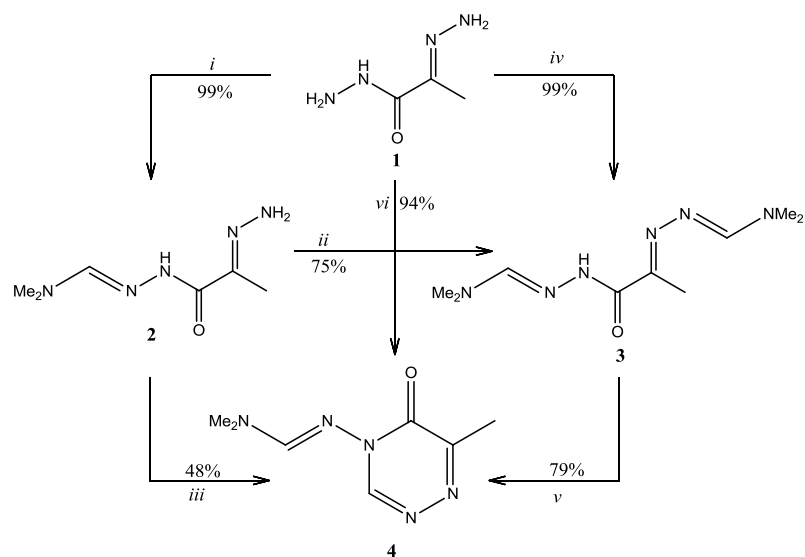

i) DMFDMA (1 eq.), $\mathrm{CH}_{3} \mathrm{OH}$, r.t., 3h.; ii) DMFDMA (1 eq.), toluene, reflux, $8 \mathrm{~h}$.; iii) DMFDMA (1 eq.), toluene, reflux, 12h.; iv) DMFDMA (2 eq.), toluene, reflux, 16h.; v) Toluene, reflux, $\mathrm{BF}_{3}, 4 \mathrm{~h}$.; vi) DMFDMA, (2 eq.), toluene, reflux, $\mathrm{BF}_{3}, 12 \mathrm{~h}$.

Scheme 1.

\section{CONCLUSION}

In conclusion, the Triazinone (4) was synthesized with good yield and easy methodology that could be used for the preparation of compounds analogs, it was observed that with the decrease of the steps, there is decrease time of reaction and increased overall yield.

\section{ACKNOWLEDGEMENTS}

The authors thank the financial support from CNPq, CAPES and Fundação Araucária.

\section{REFERENCES}

[1] KRZYSZTOF SZTANKE, K. P. M. S. M. K.-S. A. E. K. I. D. Bioorganic \& Medicinal Chemistry Letters, 19, 2009. 5095-5100. [2] RUI-YANG YANG, A. P. K. Tetrahedron Letters, 42, 2001. 4433-4435. [3] V. V. ALEKSEYEV, A. G. S. S. I. Y. Chemistry of Heterocyclic Compounds, 48, n. 3, 2012. 506-511. [4] V. L. RUSINOV, E. N. U. O. N. C. V. N. C. Russian Chemical Bulletin, 57, n. 5, 2008. 985-1014. [5] AHMAD SAM SHAWALI, S. M. S. Current Organic Chemistry, 11, n. 9, 2007. 773-799. [6] DEREK H. R. BARTON, J. C. J. W. L. T. S. Tetrahedron, 52, n. 47, 1996. 14673-1468. [7] YASSIN, F. A. Journal of Microbiology and Antimicrobials, 2, n. 7 , 